\title{
Predictors of long-term post-thrombotic syndrome following high proximal deep vein thrombosis: a cross-sectional study
}

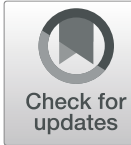

\author{
Marit Engeseth ${ }^{1,2} \mathbb{D}$, Tone Enden ${ }^{3}$, Per Morten Sandset ${ }^{1,2}$ and Hilde Skuterud Wik ${ }^{2^{*}}$
}

\begin{abstract}
Background: Post-thrombotic syndrome (PTS) is a frequent chronic complication of proximal deep vein thrombosis (DVT) of the lower limb, but predictors of PTS are not well established. We aimed to examine predictors of PTS in patients with long-term PTS following proximal DVT.

Methods: During 2006-09, 209 patients with a first time acute upper femoral or iliofemoral DVT were randomized to receive either additional catheter-directed thrombolysis or conventional therapy alone. In 2017, the 170 still-living participants were invited to participate in a cross-sectional follow-up study. In the absence of a gold standard diagnostic test, PTS was defined in line with clinical practice by four mandatory, predefined clinical criteria: 1. An objectively verified DVT; 2 . Chronic complaints (> 1 month) in the DVT leg; 3. Complaints appeared after the DVT; and 4. An alternative diagnosis was unlikely. Possible predictors of PTS were identified with multivariate logistic regression.
\end{abstract}

Results: Eighty-eight patients (52\%) were included 8-10 years following the index DVT, and 44 patients (50\%) were diagnosed with PTS by the predefined clinical criteria. Younger age and higher baseline Villalta score were found to be independent predictors of PTS, i.e., OR 0.96 (95\% Cl, 0.93-0.99), and 1.23 (95\% Cl, 1.02-1.49), respectively. Lack of iliofemoral patency at six months follow-up was significant in the bivariate analysis, but did not prove to be significant after the multivariate adjustments.

Conclusions: In long-term follow up after high proximal DVT, younger age and higher Villalta score at DVT diagnosis were independent predictors of PTS.

Keywords: Comorbidity, Deep vein thrombosis, Post-thrombotic syndrome, Predictors, Venous insufficiency

\section{Background}

Post-thrombotic syndrome (PTS) is a long-term complication in up to $50 \%$ of patients with a previous proximal deep vein thrombosis (DVT) [1-3]. PTS is a chronic syndrome with various intermittent or persistent symptoms and signs of the lower limb; typically skin discoloration, swelling, and heaviness, and in severe cases

\footnotetext{
* Correspondence: uxzwhi@ous-hf.no

${ }^{2}$ Department of Haematology, Oslo University Hospital, P.O.Box 4950 Nydalen, N-0424 Oslo, Norway

Full list of author information is available at the end of the article
}

painful venous ulcers and activity limiting venous claudication [4-8]. PTS is associated with a reduction in quality of life (QoL), high demands on health care costs, and there are few treatment options [9-12].

There is no gold standard objective test for diagnosing PTS [13]. In clinical practice, patients who present with typical lower limb symptoms and signs later than 3-6 months following an acute DVT, and with no other obvious cause, are considered to have developed PTS [14, 15]. On the other hand, in clinical trials various scorings systems have been used for the diagnosing, grading, and

(c) The Author(s). 2021 Open Access This article is licensed under a Creative Commons Attribution 4.0 International License, which permits use, sharing, adaptation, distribution and reproduction in any medium or format, as long as you give appropriate credit to the original author(s) and the source, provide a link to the Creative Commons licence, and indicate if changes were made. The images or other third party material in this article are included in the article's Creative Commons licence, unless indicated otherwise in a credit line to the material. If material is not included in the article's Creative Commons licence and your intended use is not permitted by statutory regulation or exceeds the permitted use, you will need to obtain permission directly from the copyright holder. To view a copy of this licence, visit http://creativecommons.org/licenses/by/4.0/ The Creative Commons Public Domain Dedication waiver (http://creativecommons.org/publicdomain/zero/1.0/) applies to the data made available in this article, unless otherwise stated in a credit line to the data. 
follow-up of PTS [13, 16-18]. This is problematic when comparing results across studies and when implementing research for improved post-thrombotic care $[19,20]$. In 2009, the International Society on Thrombosis and Hemostasis (ISTH) recommended the Villalta scale [13, 17] for PTS assessment in clinical research. In the absence of a gold standard test, the Villalta scale has been validated through correlations to generic and diseasespecific QoL scores [10, 21-23], and anatomic and physiologic markers [20, 24, 25].

Despite being the recommended scoring system, limitations in the diagnostic accuracy of the Villalta scale have been recognized [26-29]. The scale is unspecific and includes symptoms and signs that may occur in various other diseases [26]. Moreover, some patients with severe leg problems that obviously relate to the DVT, i.e., they appeared in the same leg with no other obvious cause(s), may not qualify as PTS by the Villalta score $[13,28,30,31]$. This typically applies to patients with activity limitations due to venous claudication [18, 27]. In a recent qualitative study, we explored the relations between the different items of the Villalta scale and the clinical characteristics and complaints described by patients with moderate and severe PTS. Our findings indicated that the Villalta scale does not capture various typical PTS complaints or reflect on the importance of PTS symptoms and signs [5]. Thus, an improved diagnostic approach for PTS seems warranted. In the absence of a gold standard diagnostic test, we used four mandatory predefined clinical PTS criteria in line with how we diagnose PTS in clinical practice $[5,32,33]$. We included any chronic complaint that had developed in the index limb following the objectively verified acute DVT, and an alternative diagnosis for the complaints had to be unlikely; hereunder excluding any preexisting comorbidity of the leg (Table 1).

As there is no curative treatment for PTS [17], identification of predictors of PTS may help identifying patients at risk of developing PTS, facilitate PTS prevention, and guide in the development toward improved PTS management and care [34]. Previous studies of PTS predictors have mainly used the Villalta scale for PTS assessment [1, $2,29,35-41]$. However, the predictors identified have not been consistent across studies and have included proximal DVT, recurrent ipsilateral DVT, provoked DVT, preexisting chronic venous insufficiency, obesity, smoking, older age, thrombophilia, deep venous reflux, and

Table 1 Four mandatory and predefined clinical criteria for PTS

1. Previous objectively verified DVT

2. Development of chronic complaints (> 1 month) in the DVT leg*

3. The chronic complaints appeared or worsened following the DVT

4. An alternative diagnosis to the patient's complaints is not likely

*Any chronic complaint developed in the limb following the DVT [5, 32] persistent venous obstruction [17, 34, 42]. Some studies have found men to be at higher risk; others have found the opposite [2, 43, 44]. Recurrent ipsilateral DVT is a strong predictor in a number of these studies, however, the magnitude of the effect differs across the studies, which can be explained by variability in study populations, and PTS definitions [17].

In the current study, we aimed to examine predictors of long-term PTS as defined by the four predefined clinical criteria in line with clinical practice [5, 32].

\section{Methods}

\section{Study population}

During 2006-2009, the Catheter-directed Venous Thrombolysis (CaVenT) study randomized 209 participants with a first-time upper femoral and/or iliofemoral DVT to receive either additional catheter-directed thrombolysis $(\mathrm{CDT})$ or conventional anticoagulant treatment. The protocol, and main outcomes from two and five years follow-up have been reported elsewhere [3, 42]. In 2017, we re-invited the 170 CaVenT participants who were still alive to participate in a cross-sectional follow-up study of long-term complications. A detailed description of the population has previously been published $[3,42]$.

\section{Variables and instruments}

At the study visit PTS was assessed with the four predefined criteria (Table 1) by an experienced study investigator (ME).

Various baseline variables from the CaVenT study were included, hereunder age, gender, smoking, and the duration of symptoms before DVT diagnosis. Localization of baseline DVT based on routine diagnostic imaging was categorized as isolated pelvic, iliofemoral, or upper femoral DVT. For predictor analysis, a variable "DVT with pelvic involvement" included both iliofemoral and isolated pelvic DVT. Other baseline variables included allocated treatment arm within the CaVenT study, D-dimer, C-reactive protein (CRP), Villalta score, and increased calf circumference. For predictor analysis, we registered D-dimer $\geq 0.5 \mu \mathrm{g} / \mathrm{mL}$ and $\mathrm{CRP} \geq 4 \mathrm{mg} / \mathrm{L}$, i.e., above the reference level. Differences in calf circumference were measured in centimeters at the level of the tuberosity of the tibia between the index leg and the contralateral leg. At baseline, DVT was categorized as provoked if occurring following trauma, immobilization, or surgery, and in patients with cancer, hormone-replacement therapy (HRT), or recent pregnancy. Variables from the six months follow-up in the CaVenT study used as possible predictors in the present study included femoropopliteal reflux, i.e., venous incompetence with reflux defined as venous valve closure time $>0.5 \mathrm{~m} / \mathrm{sec}$ on duplex ultrasound, and iliofemoral 
patency, i.e., flow in the pelvic and femoral vein with complete compressibility of the femoral vein and no functional venous obstructions, assessed by ultrasound and air plethysmography [40]. Finally, we included daily use of elastic compression stockings (ECS), and recurrent ipsilateral DVT from two and five years follow up.

\section{Statistical analyses}

Continuous variables (i.e., age, differences in leg circumference, and duration of symptoms before DVT diagnosis) are presented as mean with standard deviation (SD). Dichotomous variables (i.e., gender, daily smoking, DVT with pelvic vein involvement, left sided DVT, additional CDT, and daily use of ECS) are presented as frequencies with percentages (Table 2). To identify possible predictors of PTS, we tested whether known risk factors for PTS, additional CDT treatment, differences in leg circumference, lack of iliofemoral patency, and presence of iliofemoral reflux were differently distributed between patients with and without PTS using bivariate logistic regression. Continuous variables (i.e., age, Villalta score at baseline, duration of symptoms before DVT diagnosis, and difference in leg circumference) were not dichotomized in these analyses, but kept as continuous variables. The Wald test was used to test the level of significance. All variables with $P$-values $<0.20$ in the bivariate analyses were included in a multivariate logistic regression model with backward variable selection, until all the remaining variables were statistically significant. Differences with a P-value $<0.05$ were considered

Table 2 Demographic and clinical characteristics

\begin{tabular}{ll}
\hline Baseline & $\mathbf{N = 8 8}$ \\
\hline Age, years & $50.5(15.5)$ \\
Women & $31(35)$ \\
Daily smoking & $18(20.5)$ \\
Duration of symptoms before DVT diagnosis, days & $6.8(5.0)$ \\
Localization of DVT* & \\
$\quad$ Isolated pelvic & $3(3.4)$ \\
$\quad$ lliofemoral & $40(45.5)$ \\
$\quad$ Upper femoral & $42(47.7)$ \\
Left-sided DVT & $49(55.7)$ \\
Allocated treatment group in the CaVenT study & \\
$\quad$ Conventional anticoagulant treatment & $45(51)$ \\
$\quad$ Additional catheter-directed thrombolysis & $43(49)$ \\
Follow-up data, CaVenT & \\
Daily use of elastic compression stockings & $68(77.3)$ \\
Recurrent ipsilateral DVT† & $10(11.4)$ \\
\hline
\end{tabular}

Data are from the randomized clinical trial; the Catheter-directed Venous Thrombolysis (CaVenT) study.

Continous data are presented as mean (SD) and categoric data as number (\%). *Based on routine diagnostic imaging at baseline, $n=85$

tData from 24 to 60 months follow-up. statistically significant. Results from the bivariate and multivariate logistic regression were presented as odds ratios (OR) with 95\% confidence intervals (CI). Variables that were significant in the final model were also checked for interactions. Statistical Package for Social Sciences (SPSS) version 25 was used for all analyses (SPSS Inc., Chicago, Illinois, USA).

\section{Results}

\section{Demographic and clinical characteristics}

Eighty-eight (52\%) of the eligible CaVenT study participants were included during October 2017-June 2018. Thirty-one $(35 \%)$ of the participants were female. Mean age was 60.7 (SD 15.4) years, and mean follow-up time since index DVT was 9.5 (SD 1.2) years. Localization of index DVT, as well as other baseline and follow-up characteristics, are presented in Table 2. Based on data from the CaVenT study, the characteristics of the 88 participants and the 82 non-participants were comparable (i.e., age at DVT diagnosis, gender, localization of index DVT, PTS diagnosed by the Villalta scale at 5 years follow up, and treatment group in the CaVenT study except for comorbidity of the index leg which was present in $32(36 \%)$ of non-participants compared to $11(12.5 \%)$ of participants $(p<0.001)$. Other details have been presented elsewhere [3, 42].

When assessing PTS by the mandatory predefined clinical criteria, PTS was diagnosed in $44(50 \%)$ of the participants. Chronic complaints in the DVT limb included activity-related discomfort, pressure, aching, impaired sensitivity/paresthesia, venous ectasia, hyperpigmentation, redness, venous ulcers, heaviness, and edema. We excluded preexisting complaints including sequela after fractures, sequelae from trauma and stroke, arthrosis, varicose veins, and psoriasis arthritis. There was statistically no significant difference of PTS diagnosed by the predefined clinical criteria in the participants receiving additional CDT versus conventional anticoagulant treatment, i.e., 19 (44\%) versus 25 (56\%), respectively $(p=0.3)$.

\section{Predictors of post-thrombotic syndrome}

Younger age, higher baseline Villalta score, and lack of iliofemoral patency at six months follow-up were significantly associated with PTS in the bivariate analyses. Participants with recurrent ipsilateral DVT, and smokers, respectively, were too few to be assessed. Both DVT with pelvic vein involvement and provoked DVT had $p$-values $<0.20$ in the bivariate analyses and were included in the multivariate model. Gender, treatment with additional CDT, D-dimer $>0.5 \mu \mathrm{g} / \mathrm{mL}, \mathrm{CRP} \geq 0.4 \mathrm{mg} / \mathrm{L}$, increased leg circumference at DVT diagnosis, and duration of symptoms before DVT diagnosis, were not associated with PTS in the bivariate analyses (Table 3). In the 
Table 3 Crude and adjusted odds ratios for post-thrombotic syndrome

\begin{tabular}{|c|c|c|c|c|c|}
\hline Variable & $N$ & Crude OR $(95 \% \mathrm{Cl})$ & $P$ - value* & Adjusted OR (95\% Cl) & Adjusted $P$-value* \\
\hline \multicolumn{6}{|l|}{ Baseline } \\
\hline Age (continuous), years & 88 & $0.96(0.94-0.99)$ & 0.01 & $0.96(0.93-0.99)$ & 0.01 \\
\hline Women & 88 & $0.74(0.30-1.78)$ & 0.50 & & \\
\hline Daily smoking & 88 & $1.32(0.46-3.74)$ & 0.59 & & \\
\hline Duration of symptoms before DVT diagnosis, days & 88 & $1.02(0.94-1.11)$ & 0.55 & & \\
\hline DVT with pelvic vein involvement & 85 & $2.09(0.87-5.03)$ & 0.10 & & \\
\hline Left-sided DVT & 88 & $1.45(0.62-3.38)$ & 0.39 & & \\
\hline Additional catheter-directed thrombolysis & 88 & $1.57(0.68-3.66)$ & 0.28 & & \\
\hline Provoked DVT & 88 & $1.94(0.76-4.95)$ & 0.16 & & \\
\hline Villalta score (continuous) & 83 & $1.23(1.02-1.41)$ & 0.03 & $1.23(1.02-1.49)$ & 0.03 \\
\hline Differences in leg circumference (continuous), cm & 65 & $0.89(0.71-1.13)$ & 0.36 & & \\
\hline D-dimer $\geq 0.5 \mu \mathrm{g} / \mathrm{mL}$ & 83 & $0.65(0.10-4.09)$ & 0.65 & & \\
\hline $\mathrm{CRP} \geq 4 \mathrm{mg} / \mathrm{L}$ & 82 & $0.46(0.10-1.98)$ & 0.30 & & \\
\hline \multicolumn{6}{|l|}{ Follow-up data, CaVenT } \\
\hline Daily use of ECS & 76 & $1.48(0.32-6.69)$ & 0.61 & & \\
\hline Lack of iliofemoral patency & 86 & $2.88(1.18-7.01)$ & 0.02 & & \\
\hline Femoropoplietal reflux & 87 & $1.14(0.47-2.77)$ & 0.76 & & \\
\hline
\end{tabular}

DVT deep vein thrombosis, ECS elastic compression stockings, OR odds ratio, $C l$ confidence interval, Wald test*.

multivariate model, the two continuous variables younger age and higher baseline Villalta score were independent predictors of PTS. Age was negatively associated with PTS with an OR of 0.96 (95\% CI, 0.93-0.99), hence younger age was associated with the development of PTS. A higher symptom burden at the time of the DVT diagnosis, as assessed by the Villalta score, was associated with PTS with an OR of 1.23 (95\% CI, 1.02-1.49). We found no interactions between these two continuous variables.

\section{Discussion}

When defining PTS by four mandatory and predefined clinical criteria in line with clinical practice, we found that younger age and a higher baseline Villalta score were independent predictors of long-term PTS in patients with a prior high proximal DVT.

Our findings are likely to contribute to the limited knowledge of predictors for long-term PTS, and identifying patients at risk is an important step towards developing improved treatment strategies for the prevention of PTS [17, 45]. Also, our findings may indicate that PTS remains a common chronic complication for up to ten years following a first-time high proximal DVT. Younger age was an independent predictor of PTS which is in contrast to previous studies reporting that older age is a predictor for PTS [1, 2, 44, 46, 47]. Lower leg comorbidity is likely to be more common in older patients, and may have contributed to confounding in previous studies. This possible confounding was avoided in our study as obvious comorbid leg symptoms and signs excluded PTS according to the predefined criteria.

The baseline Villalta score is likely to indicate the symptom burden at the time of DVT diagnosis, and a higher baseline score was an independent predictor of long-term PTS. Others have also found that a higher baseline Villalta score predicts a less favorable long-term outcome. Rabinovich et al. developed a prediction model for PTS based on the SOX study and found that patients with a Villalta score $\geq 4$ at baseline, in addition to pelvic DVT and body mass index $\geq 35 \mathrm{~kg} / \mathrm{m}^{2}$, predicted increased risk of PTS [48]. In addition, Kahn et al. found that higher Villalta score at one-month post-DVT was a strong predictor for PTS [2].

Previous studies have also found iliofemoral DVT [2, 44], recurrent ipsilateral DVT [2, 39, 46, 49], and high body mass index (BMI) [29] as strong predictors for PTS $[44,48]$. DVT with pelvic vein involvement were included in our multivariate model but was not a significant predictor in our study. The incidence of recurrent ipsilateral DVT was low, and data on baseline BMI was collected only in a subset of patients. Thus, neither of these two variables could be evaluated in the present study.

The introduction of CDT for PTS prevention was based upon the "open vein hypothesis", where an accelerated thrombus removal is thought to prevent venous valve incompetence and incomplete recanalization [3, 50]. At the six months follow-up of the CaVenT trial [42] the lack of iliofemoral patency and deep venous 
reflux were found to be independent predictors of PTS in the treatment group receiving CDT; and PTS was defined by the Villalta scale [40]. Prandoni et al. reported an increased risk of PTS in patients with persistent venous obstruction or popliteal reflux at six months followup [25]. In the current study, neither lack of iliofemoral patency nor deep venous reflux came out as independent predictors of PTS. This could be due to selection bias as only $52 \%$ of the still eligible patients were included, the lack of power, or the use of a different definition of PTS.

It is acknowledged that the clinical presentation of PTS is non-specific and conditions as primary venous insuffiency, trauma, central venous hypertension, and arthrosis may present with similar clinical manifestations $[26,32]$. Moreover, reported predictors of PTS are overlapping with predictors of primary venous insufficiency $[30,34]$. Galanaud et al. used data from the REVERSE study to assess risk factors for PTS in patients with a first unprovoked proximal DVT who were free of clinically significant primary venous insufficiency with an effort to remove biased evaluation of PTS. After excluding patients with primary venous insufficiency, only obesity remained an independent predictor of PTS [29]. Previous studies have shown that Villalta scores in the ipsilateral and contralateral legs are strongly correlated, indicating that cases considered as PTS may reflect preexisting chronic venous disease [17, 26, 51, 52]. When assessing PTS by the four clinical criteria, we excluded patients with complaints likely to be explained by primary venous insufficiency and other lower limb comorbidity.

A major limitation of this study includes the PTS assessment with no previously validated diagnostic tool. We assessed PTS in line with clinical practice $[5,26,27$, 32]. The reported chronic complaints in the present study were to a great extent included in the Villalta scale. However, the scale does not include the typical pain and tightness in the thigh/calf during exercise with relief during rest, i.e., venous claudication which is often seen in persistent vein obstruction following iliofemoral DVT [53]. Furthermore, the Villalta scale does not require symptoms or signs to be chronic, or consider whether the complaints could be explained by other conditions, i.e., comorbidity, we consider the four mandatory predefined clinical criteria to be relevant and contribute to improved diagnostic accuracy. However, without a previously validated diagnostic tool, our findings can only be considered as preliminary, hypothesis generating, and further research is needed.

Another limitation was that one study investigator performed all study visits and assessments. As only 52\% of the eligible patients gave consent to participate in the current study there is a possibility for selection bias, however the participants and non-participants did not differ except for more leg comorbidity among nonparticipants [32]. Comparisons between DVT with and without pelvic involvement in our material are uncertain, as pelvic involvement was not routinely assessed in patients randomized to the control group [3]. Moreover, we were not able to assess BMI as patients' height and weight were not systematically collected at baseline. We do not have data on time in therapeutic range (TTR), thus, we were not able to evaluate the quality of anticoagulation as a possible predictor for PTS. A strength of the current study is the long follow-up time.

\section{Conclusions}

We conclude that younger age and higher Villalta score at the time of DVT diagnosis are independent predictors of long-term PTS.

\section{Abbreviations}

BMI: Body mass index; CaVenT: Catheter-directed Venous Trombolysis; CDT: Catheter-directed thrombolysis; Cl: Confidence interval; CRP: C-reactive protein; DVT: Deep vein thrombosis; ECS: Elastic compression stockings; ISTH: International Society on Thrombosis and Haemostasis; HRT: Hormonereplacement therapy; OR: Odds ratio; QoL: Quality of life; SPSS: Statistical Package for Social Sciences; PTS: Post-thrombotic syndrome

\section{Acknowledgements \\ Not applicable.}

\begin{abstract}
Authors' contributions
TE, HSW, and PMS conceived the research study design. ME performed the interviews and the clinical examinations. ME and HSW performed the analysis and interpreted the data. ME drafted the manuscript, and all authors critically revised the manuscript. The authors read and approved the final manuscript.
\end{abstract}

Funding

This current work was founded by the South-Eastern Norway Regional Health Authority.

Availability of data and materials

The datasets used in the current study are available from the corresponding author on reasonable request.

Ethics approval and consent to participate

The study was approved by the southeastern Norway Regional Committee for Medical and Health Research Ethics (approval no. 2015/1567), and adhered to the principles outlined in the Declaration of Helsinki. Written informed consent was obtained from all participants.

Consent for publication

Not applicable.

\section{Competing interests}

The authors state that they have no competing interests.

\section{Author details}

${ }^{1}$ Institute of Clinical Medicine, University of Oslo, Oslo, Norway. ${ }^{2}$ Department of Haematology, Oslo University Hospital, P.O.Box 4950 Nydalen, N-0424 Oslo, Norway. ${ }^{3}$ Division of Radiology and Nuclear medicine, Oslo University Hospital, Oslo, Norway. 
Received: 15 May 2020 Accepted: 16 December 2020 Published online: 08 January 2021

\section{References}

1. Prandoni $P$, Lensing AW, Prins MH, Frulla M, Marchiori A, Bernardi $E_{\text {, et al. }}$ Below-knee elastic compression stockings to prevent the post-thrombotic syndrome: a randomized, controlled trial. Ann Intern Med. 2004;141(4):24956.

2. Kahn SR, Shrier I, Julian JA, Ducruet T, Arsenault L, Miron MJ, et al. Determinants and time course of the postthrombotic syndrome after acute deep venous thrombosis. Ann Intern Med. 2008;149(10):698-707.

3. Enden T, Haig Y, Klow NE, Slagsvold CE, Sandvik L, Ghanima W, et al. Longterm outcome after additional catheter-directed thrombolysis versus standard treatment for acute iliofemoral deep vein thrombosis (the CaVenT study): a randomised controlled trial. Lancet. 2012;379(9810):31-8.

4. Kahn SR. The post-thrombotic syndrome: progress and pitfalls. $\mathrm{Br} J$ Haematol. 2006;134(4):357-65.

5. Engeseth M, Enden T, Andersen MH, Sandset PM, Wik HS. Does the Villalta scale capture the essence of postthrombotic syndrome? A qualitative study of patient experience and expert opinion. J Thromb Haemost. 2019;17(10): 1707-14.

6. Delis KT, Bjarnason H, Wennberg PW, Rooke TW, Gloviczki P. Successful iliac vein and inferior vena cava stenting ameliorates venous claudication and improves venous outflow, calf muscle pump function, and clinical status in post-thrombotic syndrome. Ann Surg. 2007;245(1):130-9.

7. Moffatt CJ, Doherty DC, Smithdale R, Franks PJ. Clinical predictors of leg ulcer healing. Br J Dermatol. 2010;162(1):51-8.

8. BNe A. Diseases of the Veins. London: Arnold; 1999.

9. Enden T, Wik HS, Kvam AK, Haig Y, Klow NE, Sandset PM. Health-related quality of life after catheter-directed thrombolysis for deep vein thrombosis: secondary outcomes of the randomised, non-blinded, parallel-group CaVenT study. BMJ Open. 2013;3(8):e002984.

10. Kahn SR, Shbaklo H, Lamping DL, Holcroft CA, Shrier I, Miron MJ, et al. Determinants of health-related quality of life during the 2 years following deep vein thrombosis. J Thromb Haemost. 2008;6(7):1105-12.

11. Guanella R, Ducruet T, Johri M, Miron MJ, Roussin A, Desmarais S, et al. Economic burden and cost determinants of deep vein thrombosis during 2 years following diagnosis: a prospective evaluation. J Thromb Haemost. 2011;9(12):2397-405.

12. MacDougall DA, Feliu AL, Boccuzzi SJ, Lin J. Economic burden of deep-vein thrombosis, pulmonary embolism, and post-thrombotic syndrome. Am J Health Syst Pharm. 2006;63(20 Suppl 6):S5-15.

13. Kahn SR, Partsch H, Vedantham S, Prandoni P, Kearon C. Definition of postthrombotic syndrome of the leg for use in clinical investigations: a recommendation for standardization. J Thromb Haemost. 2009;7(5):879-83.

14. Rabinovich A, Kahn SR. How I treat the postthrombotic syndrome. Blood. 2018;131(20):2215-22.

15. Kahn SR, Galanaud JP, Vedantham S, Ginsberg JS. Guidance for the prevention and treatment of the post-thrombotic syndrome. J Thromb Thrombolysis. 2016;41(1):144-53.

16. Wik HS, Ghanima W, Sandset PM, Kahn SR. Scoring Systems for Postthrombotic Syndrome. Semin Thromb Hemost. 2017.

17. Kahn SR, Comerota AJ, Cushman M, Evans NS, Ginsberg JS, Goldenberg NA, et al. The postthrombotic syndrome: evidence-based prevention, diagnosis, and treatment strategies: a scientific statement from the American Heart Association. Circulation. 2014;130(18):1636-61.

18. Soosainathan A, Moore HM, Gohel MS, Davies AH. Scoring systems for the post-thrombotic syndrome. J Vasc Surg. 2013;57(1):254-61.

19. Kahn SR, Shapiro S, Ducruet T, Wells PS, Rodger MA, Kovacs MJ, et al. Graduated compression stockings to treat acute leg pain associated with proximal DVT. A randomised controlled trial. Thromb Haemost. 2014;112(6): $1137-41$.

20. Kolbach DN, Neumann HA, Prins MH. Definition of the post-thrombotic syndrome, differences between existing classifications. Eur J Vasc Endovasc Surg. 2005;30(4):404-14.

21. Kahn SR, Hirsch A, Shrier I. Effect of postthrombotic syndrome on healthrelated quality of life after deep venous thrombosis. Arch Intern Med. 2002; 162(10):1144-8.

22. Kahn SR, Kearon C, Julian JA, Mackinnon B, Kovacs MJ, Wells P, et al. Predictors of the post-thrombotic syndrome during long-term treatment of proximal deep vein thrombosis. J Thromb Haemost. 2005;3(4):718-23.
23. Kahn SR, Desmarais S, Ducruet T, Arsenault L, Ginsberg JS. Comparison of the Villalta and Ginsberg clinical scales to diagnose the post-thrombotic syndrome: correlation with patient-reported disease burden and venous valvular reflux. J Thromb Haemost. 2006;4(4):907-8.

24. Villalta S, Prandoni P, Cogo A, Bagatella P, Piccioli A, Bernardi E, et al. The utility of non-invasive tests for detection of previous proximal-vein thrombosis. Thromb Haemost. 1995;73(4):592-6.

25. Prandoni P, Frulla M, Sartor D, Concolato A, Girolami A. Vein abnormalities and the post-thrombotic syndrome. J Thromb Haemost. 2005;3(2):401-2.

26. Galanaud JP, Holcroft CA, Rodger MA, Kovacs MJ, Betancourt MT, Wells PS, et al. Comparison of the Villalta post-thrombotic syndrome score in the ipsilateral vs. contralateral leg after a first unprovoked deep vein thrombosis. J Thromb Haemost. 2012;10(6):1036-42.

27. ten Cate-Hoek AJ, Henke PK, Wakefield TW. The post thrombotic syndrome: ignore it and it will come back to bite you. Blood Rev. 2016;30(2):131-7.

28. Strijkers $\mathrm{RH}$, Wittens $\mathrm{CH}$, Kahn SR. Villalta scale: goals and limitations. Phlebology. 2012;27(Suppl 1):130-5.

29. Galanaud JP, Holcroft CA, Rodger MA, Kovacs MJ, Betancourt MT, Wells PS, et al. Predictors of post-thrombotic syndrome in a population with a first deep vein thrombosis and no primary venous insufficiency. J Thromb Haemost. 2013;11(3):474-80.

30. Kahn SR. How I treat postthrombotic syndrome. Blood. 2009;114(21):462431.

31. Galanaud JP, Quenet S, Rivron-Guillot K, Quere I, Sanchez Muñoz-Torrero JF, Tolosa C, et al. Comparison of the clinical history of symptomatic isolated distal deep-vein thrombosis vs. proximal deep vein thrombosis in 11086 patients. J Thromb Haemost. 2009;7(12):2028-34.

32. Engeseth M, Enden T, Sandset PM, Wik HS. Limitations of the Villalta scale in diagnosing post-thrombotic syndrome. Thromb Res. 2019;184:62-6.

33. Rutjes AW, Reitsma JB, Coomarasamy A, Khan KS, Bossuyt PM. Evaluation of diagnostic tests when there is no gold standard. A review of methods. Health Technol Assess. 2007;11(50):iii, ix-51.

34. Galanaud JP, Monreal M, Kahn SR. Predictors of the post-thrombotic syndrome and their effect on the therapeutic management of deep vein thrombosis. J Vasc Surg Venous Lymphat Disord. 2016;4(4):531-4.

35. Wik HS, Jacobsen AF, Sandvik L, Sandset PM. Prevalence and predictors for post-thrombotic syndrome 3 to 16 years after pregnancy-related venous thrombosis: a population-based, cross-sectional, case-control study. J Thromb Haemost. 2012;10(5):840-7.

36. Ten Cate-Hoek AJ, Ten Cate H, Tordoir J, Hamulyak K, Prins MH. Individually tailored duration of elastic compression therapy in relation to incidence of the postthrombotic syndrome. J Vasc Surg. 2010;52(1):132-8.

37. Comerota AJ, Grewal N, Martinez JT, Chen JT, Disalle R, Andrews L, et al. Postthrombotic morbidity correlates with residual thrombus following catheter-directed thrombolysis for iliofemoral deep vein thrombosis. J Vasc Surg. 2012;55(3):768-73.

38. Prandoni P, Lensing AW, Cogo A, Cuppini S, Villalta S, Carta M, et al. The long-term clinical course of acute deep venous thrombosis. Ann Intern Med. 1996;125(1):1-7.

39. Bouman AC, Smits JJ, Ten Cate H, Ten Cate-Hoek AJ. Markers of coagulation, fibrinolysis and inflammation in relation to post-thrombotic syndrome. J Thromb Haemost. 2012;10(8):1532-8.

40. Haig Y, Enden T, Slagsvold CE, Sandvik L, Sandset PM, Klow NE. Residual rates of reflux and obstruction and their correlation to post-thrombotic syndrome in a randomized study on catheter-directed thrombolysis for deep vein thrombosis. J Vasc Surg Venous Lymphat Disord. 2014;2(2):123-30.

41. Mol GC, Dronkers CEA, van de Ree MA, van der Pas SL, Tegelberg-Stassen $M$, Sanders FBM, et al. Elastic compression stockings one year after DVT diagnosis: who might discontinue? Thromb Res. 2019;173:35-41.

42. Haig Y, Enden T, Grotta O, Klow NE, Slagsvold CE, Ghanima W, et al. Postthrombotic syndrome after catheter-directed thrombolysis for deep vein thrombosis (CaVenT): 5-year follow-up results of an open-label, randomised controlled trial. Lancet Haematol. 2016;3(2):e64-71.

43. Stain M, Schonauer $V$, Minar E, Bialonczyk C, Hirschl M, Weltermann A, et al. The post-thrombotic syndrome: risk factors and impact on the course of thrombotic disease. J Thromb Haemost. 2005;3(12):2671-6.

44. Tick LW, Kramer MH, Rosendaal FR, Faber WR, Doggen CJ. Risk factors for post-thrombotic syndrome in patients with a first deep venous thrombosis. J Thromb Haemost. 2008;6(12):2075-81.

45. Rabinovich A, Kahn SR. The postthrombotic syndrome: current evidence and future challenges. J Thromb Haemost. 2017;15(2):230-41. 
46. Schulman S, Lindmarker P, Holmstrom M, Larfars G, Carlsson A, Nicol P, et al. Post-thrombotic syndrome, recurrence, and death 10 years after the first episode of venous thromboembolism treated with warfarin for 6 weeks or 6 months. J Thromb Haemost. 2006:4(4):734-42.

47. van Dongen CJ, Prandoni P, Frulla M, Marchiori A, Prins MH, Hutten BA. Relation between quality of anticoagulant treatment and the development of the postthrombotic syndrome. J Thromb Haemost. 2005;3(5):939-42.

48. Rabinovich A, Ducruet T, Kahn SR. Development of a clinical prediction model for the postthrombotic syndrome in a prospective cohort of patients with proximal deep vein thrombosis. J Thromb Haemost. 2018;16(2):262-70.

49. Prandoni P, Villalta S, Bagatella P, Rossi L, Marchiori A, Piccioli A, et al. The clinical course of deep-vein thrombosis. Prospective long-term follow-up of 528 symptomatic patients. Haematologica. 1997;82(4):423-8.

50. Vedantham S, Goldhaber SZ, Julian JA, Kahn SR, Jaff MR, Cohen DJ, et al. Pharmacomechanical catheter-directed thrombolysis for deep-vein thrombosis. N Engl J Med. 2017;377(23):2240-52.

51. Utne KK, Ghanima W, Foyn S, Kahn S, Sandset PM, Wik HS. Development and validation of a tool for patient reporting of symptoms and signs of the post-thrombotic syndrome. Thromb Haemost. 2016;115(2):361-7.

52. Van der Velden SK, Shadid NH, Nelemans PJ, Sommer A. How specific are venous symptoms for diagnosis of chronic venous disease? Phlebology. 2014:29(9):580-6.

53. Delis KT, Bountouroglou D, Mansfield AO. Venous claudication in iliofemoral thrombosis: long-term effects on venous hemodynamics, clinical status, and quality of life. Ann Surg. 2004;239(1):118-26.

\section{Publisher's Note}

Springer Nature remains neutral with regard to jurisdictional claims in published maps and institutional affiliations.

Ready to submit your research? Choose BMC and benefit from:

- fast, convenient online submission

- thorough peer review by experienced researchers in your field

- rapid publication on acceptance

- support for research data, including large and complex data types

- gold Open Access which fosters wider collaboration and increased citations

- maximum visibility for your research: over $100 \mathrm{M}$ website views per year

At $\mathrm{BMC}$, research is always in progress.

Learn more biomedcentral.com/submissions 